Diabetologia $9,380-383(1973)$

(C) by Springer-Verlag 1973

\title{
Daily Production and Metabolic Clearance of Growth Hormone in Juvenile Diabetes Mellitus
}

\author{
M.A. Sperling, F. Wollesen and P.V. DeLamater \\ UCLA School of Medicine, Harbor General Hospital Campus, Division of Endocrinology, 1000 West Carson Street, \\ Torrance, California 90509, USA
}

Received: March 12, 1973, and in revised form: April 28, 1973

\begin{abstract}
Summary. Daily production (PR) of human growth hormone (HGH) was calculated in patients with juvenile diabetes and control subjects by determining metabolic clearance rate $(\mathrm{MCR})$ of ${ }^{131 \mathrm{I}} \mathrm{HGH}$, at equilibrium, and mean endogenous HGH levels throughout a $24 \mathrm{~h}$ day. Half hourly sampling or a constant withdrawal pump were used to obtain an integrated mean endogenous HGH level. MCR (liters/day) was significantly reduced in all diabetic subjects both in absolute terms $(96 \pm 15 \mathrm{vs} 274 \pm$ $37)$ and relative to surface area $(62 \pm 8$ vs $171 \pm 21)(p<$ $0.01)$. Mean HGH levels were $8.4 \mathrm{ng} / \mathrm{ml}$ in the diabetics
\end{abstract}

and $5.5 \mathrm{ng} / \mathrm{ml}$ in age matched controls. Daily HGH PR in the diabetic subjects (339 to $1365 \mu \mathrm{g} / \mathrm{day}$ ) did not exceed values in the control subjects $(1005-1426 \mu \mathrm{g} / \mathrm{day})$. The results indicate that the elevated plasma HGH levels and increased HGH response to stimuli observed in diabetes, reflect reduced metabolic clearance, rather than increased. pituitary secretion.

Key words: Growth Hormone, juvenile diabetes, metabolic clearance, integrated mean levels, daily production.
There is now convincing evidence from a number of studies that human growth hormone (HGH) can be diabetogenic in man [1]. However, whether excessive endogenous $\mathrm{HGH}$ secretion occurs or plays a role in the pathogenesis and complications of juvenile diabetes remains controversial. In support of such a concept, studies in patients with insulin dependent juvenile diabetes have documented higher plasma levels of $\mathrm{HGH}$ during the course of a normal $24 \mathrm{~h}$ day [2], or in response to stimulation with arginine [3], glucagon [3] or exercise [4] when compared to normal subjects. Furthermore, elevated levels of HGH following tolbutamide administration have been reported in "prediabetic" subjects [5]. It has been commonly implied that these elevated plasma levels indicate that pituitary release and/or secretion of HGH is increased in the diabetic state. However, elevated hormone levels could be present as a result of increased secretion or decreased metabolic blood clearance (MCR). The present study, designed to resolve this question, provides for the first time data on the integrated production rate of growth hormone in patients with insulin dependent juvenile diabetes of recent onset. In addition, the results confirm the recently reported reduction of HGH MCR in patients with diabetes $[6,7]$.

\section{Materials and Methods}

A. Subjects. Seven patients with juvenile onset, insulin dependent diabetes were studied; they ranged in age from 12 to 33 years. The duration of disease was 3-5 years except for patient 1 , whose disease had been present for 12 years. This patient had undergone hypophysectomy 3 years previously in an attempt to control diabetic retinopathy. The degree of glycosuria and daily insulin dosage varied markedly in these pa- tients. However, there was no elinical or laboratory evidence of liver disease and proteinuria was present only in case 1.

The control group consisted of eight subjects, four without a family history of diabetes, and four healthy siblings of patients with juvenile onset diabetes. None of these siblings had any significant disturbance in glucose tolerance. Studies were performed in a clinical study center after an overnight fast. The subjects were at rest, fasting throughout the study of metabolic clearance, and had received Lugol's iodine prior to infusion of radioactive growth hormone. Informed consent was obtained in each case. In the diabetic subjects the morning dose of insulin was omitted and given at the conclusion of the period of study of metabolic clearance.

B. Metabolic Clearance Rate of ${ }^{13} I$ I HGH. The MCR of ${ }^{131} \mathrm{I}$ labelled $\mathrm{HGH}\left(\mathrm{HGH}^{*}\right)$ was determined by the constant infusion method of Tait [8] as previously applied to growth hormone by Taylor et al., [7] Mac Gillivray et al., [9] and Kowarski et al. [10].

Growth hormone (supplied by the National Pituitary Agency) was iodinated to a specific activity of $50-150 \mu \mathrm{Ci} / \mu \mathrm{g}$ by the chloramine-T method of Greenwood et al., [11] using a Sephadex G-50 column previously washed with $2 \%$ human serum albumin. Column eluate fractions of $0.5 \mathrm{ml}$ were collected into tubes containing $0.1 \mathrm{ml}$ of $2 \%$ human serum albumin; samples from the protein peak were tested for immunoreactivity by a double antibody radioimmunoassay (RIA) procedure using excess rabbit anti-HGH serum. The fraction with the greatest immunoreactivity $(80 \%$ or greater) was sterilized by Millipore filtration, and cultured (aerobically and anaerobically) prior to infusion. The interval between iodination and infusion was usually 3 days and did not exceed 5 days. 
Approximately $15-20 \mu \mathrm{Ci}$ of $\mathrm{HGH} *$ was dissolved in $50 \mathrm{ml}$ of $0.9 \%$ saline. After a priming dose of $3-5$ $\mu \mathrm{Ci}$, constant infusion of a further $12-15 \mu \mathrm{Ci}$ was maintained for $150 \mathrm{~min}$ via a scalp needle in an antecubital vein, using a Harvard constant infusion pump. Samples of blood were obtained from a scalp needle (maintained patent with saline) in a contralateral antecubital vein prior to, and at $30,60,90,120,130$ and 140 min after commencing the infusion. At the end of this period the infusion needle was withdrawn and the infusate continued at the same rate into 3 collecting tubes for an exact period of 5 or 10 min each.

To determine a mean endogenous HGH level, blood samples were collected at $30 \mathrm{~min}$ intervals for $24 \mathrm{~h}$ in 4 diabetic and 4 control subjects. During this period subjects were allowed to wallk about and diabetic subjects received their appropriate diet and in-
However, the mean of the values at 120,130 and 140 min and the mean of the 3 infusate samples were used for calculation.

The infusate was at least $80 \%$ precipitable on the day of study. Results are expressed in liters/day and liters/meters square/day by the appropriate corrections.

D. Determination of Endogenous HGH. Endogenous HGH levels were determined by a double antibody RIA, previously described from this laboratory [12] using ${ }^{125} \mathrm{I} \mathrm{HGH}$ as the label. Samples, were assayed at two dilutions. At least 6 weeks elapsed from infusion of HGH* to determination of endogenous $\mathrm{HGH}$, to allow for decay of ${ }^{131}$.

E. Production Rate. The production rate (PR) was calculated as: PR $(\mu \mathrm{g} / 24 \mathrm{~h})=\mathrm{MCR} X$ mean endogenous $\mathrm{HGH}$ concentration $(\mathrm{ng} / \mathrm{ml})$.

Table 1. Metabolie clearance of growth hormone in normal subjects and patients with diabetes mellitus

\begin{tabular}{|c|c|c|c|c|c|c|c|c|c|c|c|}
\hline \multicolumn{6}{|l|}{ Diabetic } & \multicolumn{6}{|l|}{ Normal } \\
\hline Patient & Age & Sex & $\begin{array}{l}\text { Surface } \\
\text { area in } \\
\text { meters }{ }^{2}\end{array}$ & $\begin{array}{l}\text { MCR } \\
\text { liters/day }\end{array}$ & $\begin{array}{l}\text { MCR } \\
\text { liters } / \mathrm{m}^{2} / \text { day }\end{array}$ & Subject & Age & Sex & $\begin{array}{l}\text { Surface } \\
\text { area in } \\
\text { meters }^{2}\end{array}$ & $\begin{array}{l}\text { MCR } \\
\text { liters/day }\end{array}$ & $\begin{array}{l}\text { MCR } \\
\text { liters } / \mathrm{m}^{2} / \text { day }\end{array}$ \\
\hline 1 & 33 & $\mathrm{~F}$ & 1.8 & 132 & 73 & 1 & 35 & M & 1.81 & 456 & 252 \\
\hline 2 & 16 & $\mathbf{F}$ & 1.6 & 148 & 93 & 2 & 33 & $\mathrm{~F}$ & 1.54 & 425 & 276 \\
\hline 3 & 20 & $\mathbf{F}$ & 1.65 & 90 & 55 & 3 & 33 & M & 1.80 & 239 & 133 \\
\hline 4 & 12 & $\mathrm{~F}$ & 1.16 & 55 & 47 & 4 & 27 & $\mathrm{M}$ & 1.75 & 221 & 126 \\
\hline 5 & 13 & M & 1.55 & 125 & 81 & $* 5$ & 17 & $\mathrm{~F}$ & 1.73 & 248 & 143 \\
\hline 6 & 14 & M & 1.3 & 68 & 52 & $* 6$ & 15 & $\mathrm{~F}$ & 1.65 & 219 & 133 \\
\hline 7 & 16 & $\mathrm{~F}$ & 1.7 & 55 & 32 & $* 7$ & 13 & $\mathrm{M}$ & 1.42 & 205 & 144 \\
\hline \multicolumn{4}{|c|}{ Mean \pm SEM } & $96 \pm 15$ & $62 \pm 8$ & $* 8$ & 9 & $\mathrm{M}$ & 1.12 & $\begin{array}{l}179 \\
274 \pm 37\end{array}$ & $\begin{array}{l}160 \\
171 \pm 21\end{array}$ \\
\hline
\end{tabular}

MCR-liters/day $p<0.01$.

MCR-Iiters $/ \mathrm{m}^{2} /$ day $p<0.01$.

* Sibling of a diabetic.

sulin therapy. To obtain an even more accurate integrated mean endogenous HGH level, blood was withdrawn in 2 diabetic patients at a continuous rate of $1 \mathrm{ml}$ per hour by a Sigmamotor constant withdrawal pump, as recently described by Kowarske et al., [10].

$C$. Determination of $M C R$ 131 I HGH. The measurement of immunoprecipitable $\mathrm{HGH}$ was begun within $3 \mathrm{~h}$ after ending the infusion in each subject. Duplicate $0.5-1.0 \mathrm{ml}$ samples of plasma and infusate were incubated with excess rabbit anti-HGH serum for $18-24$ $h$ at room temperature and precipitated with goat anti-rabbit gammaglobulin serum. Precipitable radioactivity was measured in an automatic gamma spectrometer. Background counts and counts in a plasma sample without first antibody were subtracted. MCR was calculated from the formula of Tait:

$\operatorname{MCR}(\mathrm{ml} / \mathrm{min})=$

Rate of infused precipitable ${ }^{131} \mathrm{I} \mathrm{HGH}(\mathrm{cpm} / \mathrm{min})$ Plasma precipitable ${ }^{131}$ I HGH $(\mathrm{cpm} / \mathrm{ml})$

This formula requires that equilibrium be established and this was considered to be present when the plasma precipitable ${ }^{131} \mathrm{I}$ labelled HGH reached stable levels. Fquilibrium was achieved by $90 \mathrm{~min}$ in all cases.

\section{Results}

Table 1 compares the HGH* MCR in the diabetic and normal subjects. In the diabetic subjects the mean MCR was $96 \pm 15$ liters/day (Mean \pm SEM) compared to $274+37$ liters/day for normal subjects. When correction was made for surface area, the MCR in diabetios was $62 \pm 8.0 \mathrm{l} / \mathrm{M}^{2} /$ day compared to $171 \pm 21$ $1 / \mathrm{M}^{2} /$ day for the normal subjects. Comparison by Students $t$ test indicates that these differences are statistically significant $(p<0.01)$ both for the absolute values and after correction for surface area. The reduced MCR was also apparent in the subject who had undergone hypophysectomy and whose endogenous HGH levels were undetectable, except on 2 occasions in samples collected over a $24 \mathrm{~h}$ period (as shown in Fig. 1). Fig. 1 also shows the wide fluctuations in growth hormone concentration in 2 of the diabetic subjects. The horizontal lines indicate the mean growth hormone levels in the 2 subjects whose blood was ob. tained via the constant withdrawal pump. Despite the wide fluctuations, the mean HGH levels determined by the different sampling techniques were similar in the diabetic subjects. The mean HGH level in the entire 
diabetic group $(8.4 \pm 0.58)$ was significantly higher $(p<0.01)$ than the mean of the normal group $(5.6 \pm$ $0.47)$.

Table 2 lists the calculated production rate of $\mathrm{HGH}$ in 6 diabetic and 4 control subjects. No significant differences were present. In addition, among the diabetic group, none exceeded the production rates previously reported in normal subjects of comparable age $[9,10]$ when studied by similar techniques. from the MCR and the endogenous concentrations. In the case of HGH this has presented some difficulty since the endogenous concentration fluctuates considerably, and particularly in diabetic subjects [2]. Indeed, in the only other report in which growth hormone production rates in patients with diabetes mellitus were estimated, the mean endogenous HGH during the equilibrium period of MCR was used [6]. This will clearly not take account of spontaneous daily

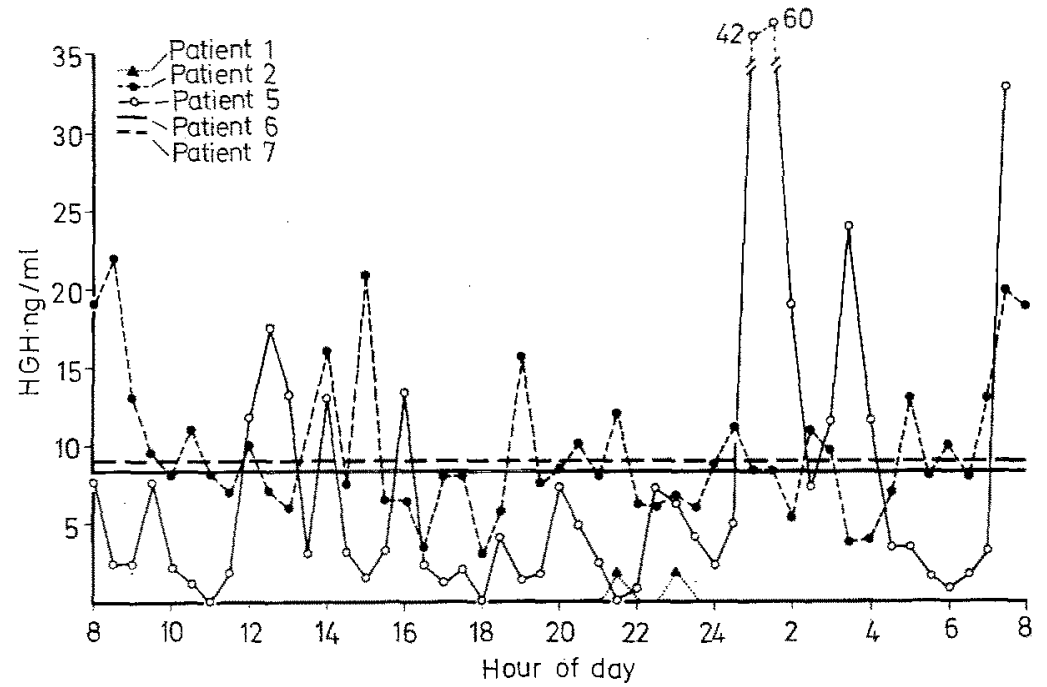

Fig. 1. Plasma growth hormone patterns in patients with juvenile diabetes. Patient 1 had undergone hypophysectomy. The horizontal lines represent the integrated mean endogenous growth hormone level determined on blood collected via a constant withdrawal pump

Table 2. Growth hormone production rates in patients with diabetes mellitus and control subjects

\begin{tabular}{|c|c|c|c|c|c|c|c|}
\hline \multicolumn{4}{|l|}{ Diabetic } & \multicolumn{4}{|l|}{ Control } \\
\hline Patient & $\begin{array}{l}\text { MCR } \\
\text { liters/day }\end{array}$ & $\begin{array}{l}\text { Mean HGH level } \\
\mathrm{ng} / \mathrm{ml}\end{array}$ & $\begin{array}{l}\text { Production rate } \\
\mu g / 24 h\end{array}$ & Subject & $\begin{array}{l}\text { MCR } \\
\text { liters/day }\end{array}$ & $\begin{array}{l}\text { Mean HGH level } \\
\mathrm{ng} / \mathrm{ml}\end{array}$ & $\begin{array}{l}\text { Production rate } \\
\mu \mathrm{g} / 24 \mathrm{~h}\end{array}$ \\
\hline 1 & 132 & 1.9 & 251 & +5 & 248 & 5.75 & 1426 \\
\hline 2 & 148 & 9.22 & 1365 & +6 & 219 & 4.77 & 1045 \\
\hline 4 & 55 & 6.16 & 339 & +7 & 205 & 4.90 & 1005 \\
\hline 5 & 125 & 9.27 & 1159 & +8 & 179 & 6.79 & 1215 \\
\hline 6 & 68 & 8.35 & 568 & & & & \\
\hline 7 & 55 & 9.0 & 495 & & & & \\
\hline Mean & 97 & $8.4^{*}$ & $785 *$ & & 212 & 5.6 & 1173 \\
\hline$\pm \mathrm{SEM}$ & 17 & 0.58 & 201 & & 14 & 0.47 & 96 \\
\hline
\end{tabular}

* Excluding patient 1 who had undergone hypophysectomy.

$\dagger$ Sibling of a diabetic.

\section{Discussion}

The mean MCR of HGH measured in the present normal subjects is similar to that previously reported $[6,7,9]$. The validity of the determination of metabolic clearance of endogenous HGH by means of constant infusion to equilibrium of $\mathrm{HGH}^{*}$ has been confirmed by a number of investigators. These studies have shown that infused $\mathrm{HGH}^{*}$ is cleared from the plasma at the same rate as infused unlabelled $\mathrm{HGH}$ or endogenous $\mathrm{HGH}$, and that this clearance is independent of the plasma concentration of $\mathrm{HGH}[6,7,9,13]$. The daily production rate of a hormone can be determined and particularly of nocturnal oscillations and, hence, may underestimate daily secretion rate. To circumvent this problem, frequent blood sampling over a $24 \mathrm{~h}$ period to calculate a mean endogenous HGH level has been used to determine $\mathrm{HGH}$ production rate [9]. A refinement to this approach has been the use of a constant withdrawal pump [10]. Excluding the patient who had undergone hypophysectomy the mean daily HGH level in our patients was $8.4 \mathrm{ng} / \mathrm{ml}$, compared to a level of $7.3 \mathrm{ng} / \mathrm{ml}$ previously reported, in patients with diabetes, by Hansen and Johansen [2]. Moreover, these values were significantly higher than those in our normal subjects. Because of these high endogenous 
$\mathrm{HGH}$ levels, as well as the augmented HGH responses to a variety of stimuli in diabetic and "prediabetic" subjects $[3,5]$, it has been implied that increased secretion of growth hormone may be a feature of the diabetic state and might play a role in the pathogenesis and/or complications of diabetes mellitus [14].

However, the present results demonstrate clearly that the daily production rate of $\mathrm{HGH}$ in patients with diabetes is not increased. Although the mean plasma HGH levels were elevated, the MCR was consistently reduced and the calculated production rate of HGH did not exceed values in the control group or the values of normal children and adults, as previously published $[9,10]$.

The mechanism for the reduced clearance of HGH in diabetic subjects is not defined, although it appears to be a consistent finding $[6,7]$. In normal subjects the liver is the major site of clearance of plasma HGH [15]. Since most of our subjects had their disease for less than 5 years our results would support the concept that an early alteration of hepatic clearance of $\mathrm{HGH}$ is characteristic of diabetes mellitus [7]. Thus, it would seem likely that the elevated plasma levels of HGH in patients with diabetes mellitus reflect the reduced clearance, while daily production rate remains normal. Whether the "continuous" elevated plasma HGH levels contribute to the complications of diabetes cannot be ascertained from the present study.

Acknowledgements. We gratefully acknowledge the advice and helpful criticism of Dr. Delbert Fisher throughout this work. Our appreciation is extended to the nursing staff of the Clinical Study Center, Harbor General Hospital, and to M. Kazenelson for technical assistance.

This work was supported in part by a grant (RR 00425) from the General Clinical Research Center Program of the Division of Research Resources, National Institutes of Health.

\section{References}

1. Boshell, B.R., Chaudalia, H. B.: Hormonal interrelationships. In: Diabetes Mellitus; Theory and Practice, p. 96, Ellenberg, M., Rifkin, H. (Eds.). New York: MeGraw-Hill 1970.

2. Hansen, Aa.P., Johansen, K.: Diurnal patterns of blood glucose, serum free fatty acids, insulin, glucagon and growth hormone in normal and juvenile diabetics. Diabetologia 6, 27-33 (1970).
3. Drash, A., Field, J.B., Garces, L.Y., Kenny, F.M., Mintz, D., Vasquez, A.M.: Endogenous insulin and growth hormone response in children with newly diagnosed diabetes mellitus. Pediat. Res. 2, 94-102 (1968).

4. Hansen, Aa.P.: Abnormal serum growth hormone response to exercise in juvenile diabetics. J. clin. Invest. 49, 1467- 1478 (1970).

5. Boden, G.J., Soeldner, S., Gleason, R.W., Marble, A.: Elevated serum human growth hormone and decreased serum insulin in prediabetic males after intravenous tolbutamide and glucose. J. clin. Invest. 47, $729-739$ (1968).

6. Taylor, A.L., Finster, J.L., Mintz, D.H.: Metabolic clearance and production rates of human growth hormone. J. clin. Invest. 48, 2349-2358 (1969).

7. Lipman, R.L., Taylor, A., Conly, P., Mintz, D.H.: Metabolic clearance rate of growth hormone in juvenile diabetes mellitus. Diabetes 21, 175-177 (1972).

8. Tait, J.F.: Review: The use of isotope steroids for measurement of production rates in vivo. J. clin. Endocr. 23, 1285-1297 (1963).

9. MacGillivray, M.H., Frohman, L.A., Doe, J.: Metabolic clearance and production rates of human growth hormone in subjects with normal and abnor. mal growth. J. clin. Endocr. 30, 632-638 (1970).

10. Kowarski, A., Thompson, R.G., Migeon, C.J., Blizzard, R.M.: Determination of integrated plasma concentrations and true secretion rates of human growth hormone. J. clin. Endocr. 32, 356-360 (1971).

11. Greenwood, F.C., Hunter, W.M., Glover, J.S.: The preparation of 131 I labeled human growth hormone of high specific radioactivity. Biochem J. 89, 114-123 (1963).

12. Odell, W.D., Rayford, P.L., Ross, G.T.: Simplified, partially automated method for radioimmunoassay of human thyroid stimulating, growth, luteinizing, and follicle stimulating hormones. J. Lab. clin. Med. 70, $973-980$ (1967).

13. Cameron, D.P., Burger, H.G., Catt, K.J., Doig, A.: Metabolic clearance rate of radioiodinated human growth hormone in man. J. elin. Invest. 48, 1600$1608(1969)$.

14. Lundbaek, K., Christensen, N.J., Jensen, V.A., Johansen, K., Olsen, T.S. Hansen, Aa. P., Orskov, H., Osterby, R.: Diabetes, diabetic angiopathy, and growth hormone. Lancet 1970 II, $131-133$.

15. Taylor, A.L., Lipman, R.L., Salam, A., Mintz, D.H. : Hepatic clearance of human growth hormone. J. clin. Endocr. 34, 395-399 (1972).

Mark A. Sperling, M. B., MRACP

Assistant Professor of Pediatrics

U.C.L.A. School of Medicine

Harbor General Hospital Campus

Division of Endocrinology

1000 West Carson Street

Torrance, California 90509

USA 